\title{
MENGAPRESIASIKAN HASIL PRESTASI BELAJAR IPA PADA MATERI SISTEM GERAK MANUSIA MELALUI DISVERSITY OF STUDENT STRATEGY LEARNING SEBAGAI METODE PEMBELAJARAN SISWA KELAS VIII SMPN 1 SEKARAN
}

\begin{abstract}
Suharno
SMP Negeri 1 Sekaran, Kab. Lamongan

INFO ARTIKEL

Diterima:14-01-2020

Disetujui: 12-02-2020

Kata Kunci:

Prestasi Belajar, IPA,

Sistem Gerak, DSTL

Abstrak: Penelitian ini bertujuan untuk mengetahui hasil prestasi belajar IPA pada sistem gerak manusia dengan menggunakan metode Diversity of Student Stategy Learning (Strategi Pembelajaran yang mempertimbangkan keragaman siswa). Penelitian ini termasuk dalam penelitian tindakan kelas yang dirancang menjadi dua siklus. Setiap siklus terdiri atas perencanaan, pelaksanaan, observasi, dan refleksi. Berdasarkan hasil penelitian yang telah dilakukan, maka diperoleh hasil, yaitu kemampuan dasar pada materi sistem gerak pada manusia dapat tercapai dengan baik. Hal ini dapat terlihat pada hasil evaluasi siswa yang mencapai ketuntasan 78,25\%. Data tersebut dijadikan dasar untuk merancang siklus 1, sehingga diperoleh hasil aktifitas siswa yang memiliki aktifitas baik dalam kegiatan belajar sebanyak $17(68 \%)$ dan sedang sebanyak $4(16 \%)$ serta sebanyak $4(16 \%)$ menunjukkan aktifitas kurang. Sedangkan hasil pengamatan dari sudut perhatian siswa dalam kegiatan belajar, siswa yang memiliki perhatian baik sebanyak $9(36 \%)$, yang memiliki perhatian sebanyak 6 (24\%) dan perhatian kurang 10 (40\%). Penggunan metode Diversity of Student Stategy Learning dapat meningkatkan aktifitas dan perhatian siswa pada pelajaran Biologi/IPA belum dinyatakan Tuntas. maka perlu diadakan kegiatan penelitian pada siklus yang ke 2, sehingga diperoleh hasil aktifitas siswa yang memiliki aktifitas baik dalam kegiatan belajar sebanyak 21 (84\%) dan sedang sebanyak $2(8 \%)$ serta sebanyak $2(8 \%)$ menunjukkan aktifitas kurang. Sedangkan hasil pengamatan dari sudut perhatian siswa dalam kegiatan belajar, siswa yang memiliki perhatian baik sebanyak $19(76 \%)$, perhatian orang tua sebanyak $4(16 \%)$ dan perhatian kurang 2 (8\%). Maka, dapat disimpulkan bahwa dengan metode Diversity of Student Stategy Learning (Strategi Pembelajaran yang mempertimbangkan keragaman siswa) dapat meningkatkan aktifitas dan perhatian siswa pada pelajaran Biologi/IPA. Dengan menggunakan metode Diversity of Student Stategy Learning
\end{abstract}

\begin{abstract}
This study aims to determine the results of natural science learning achievement in the human motion system by using the Diversity of Student Strategic Learning method (Learning Strategies that take account of student diversity). This research was included in a class action research that was designed into two cycles. Each cycle consists of planning, implementing, observing, and reflecting. Based on the results of research that has been done, the results obtained, namely the basic capabilities of the material motion system in humans can
\end{abstract}


KARANGAN: Jurnal Kependidikan, Pembelajaran, dan Pengembangan, Vol 02, No 01, Bln Feb, Tahun 2020, Hal $32-41$

be achieved properly. This can be seen in the results of student evaluations that reach $78.25 \%$ completeness. The data is used as a basis for designing cycle 1 , so as to obtain the results of the activities of students who have good activities in learning activities as many as $17(68 \%)$ and as many as $4(16 \%)$ and as many as $4(16 \%)$ indicate less activity. While observations from the point of view of students' attention in learning activities, students who have good attention are $9(36 \%)$, who have attention as much as $6(24 \%)$ and less attention is $10(40 \%)$. The use of the Diversity of Student Strategic Learning method can increase the activities and attention of students in Biology / Natural Sciences lessons yet to be declared Completed. then the research activities need to be held in the second cycle, so that the results obtained by students who have good activities in learning activities as many as $21(84 \%)$ and as many as $2(8 \%)$ and as many as 2 (8\%) indicate less activity. While observations from the point of view of students 'attention in learning activities, students who have good attention are 19 (76\%), parents' attention are $4(16 \%)$ and attention is less 2 $(8 \%)$. So, it can be concluded that the Diversity of Student Strategic Learning method (Learning Strategies that considers student diversity) can increase student activities and attention in Biology / Natural Sciences. By using the Diversity of Student

Alamat Korespondensi: Strategic Learning method.

SMP Negeri 1 Sekaran

Desa Kudikan, Kecamatan Sekaran, Kab. Lamongan, Jawa Timur

Surel: suharnostitaf@gmail.com

Melihat Dunia Pengajaran saat ini pada umumnya setiap orang menyadari arti pentingnya pendidikan, baik untuk perkembangan pribadi maupun untuk kemajuan bangsa dan negara. Pendidikan sudah menjadi kebutuhan dasar seperti kebutuhan sandang, pangan, papan serta kebutuhan kesehatan. Pendidikan adalah salah satu factor penunjang bagi kemajuan seluruh bangsa untuk mencapai tujuan pembangunan nasional, yaitu menuju masyarakat adil dan makmur materiil dan spirituil berdasarkan Pancasila. Pendidikan sebagai suatu proses pembinaan manusia yang berlangsung seumur hidup, materi pembelajaran yang diajarkan di sekolah memiliki peranan sangat penting, yaitu memberikan kesempatan kepada peserta didik untuk terlibat langsung dalam berbagai pengalaman belajar melalui aktivitas dalam pembelajaran, yang terpilih yang dilakukan secara sistematis.

Pembekalan pengalaman belajar itu diarahkan untuk membina pertumbuhan fisik dan pengembangan psikis yang lebih baik, sekaligus membentuk pola hidup sehat dan bugar sepanjang hayat. Pendidikan memiliki sasaran pedagogis, oleh karena itu pendidikan kurang lengkap tanpa adanya Pembelajaran Biologi/IPA, karena gerak sebagai aktivitas dalam pembelajaran adalah dasar bagi manusia untuk mengenal dunia dan dirinya sendiri yang secara alami berkembang searah dengan perkembangan zaman. Selama ini telah terjadi kecenderungan dalam memberikan makna mutu pendidikan yang hanya dikaitkan dengan aspek kemampuan kognitif. Pembelajaran Biologi/IPA merupakan bagian integral dari pendidikan secara keseluruhan, bertujuan untuk mengembangkan aspek kognitif dalam pembelajaran, keterampilan gerak, keterampilan berfikir kritis, keterampilan sosial, penalaran, stabilitas emosional, tindakan moral, aspek pola hidup sehat dan pengenalan lingkungan bersih melalui aktivitas dalam pembelajaran, terpilih yang direncanakan secara sistematis dalam rangka mencapai tujuan pendidikan nasional. 
Pandangan ini telah membawa akibat terabaikannya aspek-aspek moral, akhlak, budi pekerti, seni, psikomotor, serta life skill.

Dengan diterbitkannya Undang-undang Nomor 20 Tahun 2003 tentang Sistem Pendidikan Nasional dan Peraturan Pemerintah Nomor 19 Tahun 2004 tentang Standar Nasional Pendidikan akan memberikan peluang untuk menyempurnakan kurikulum yang komprehensif dalam rangka mencapai tujuan pendidikan nasional. Dalam Kegiatan Pembelajaran Biologi/IPA memerlukan media untuk mendorong pertumbuhan fisik, perkembangan psikis, keterampilan motorik, pengetahuan dan penalaran, penghayatan nilai-nilai (sikap-mentalemosional-sportivitas-spiritual-sosial), serta pembiasaan pola hidup sehat yang bermuara untuk merangsang pertumbuhan dan perkembangan kualitas fisik dan psikis yang seimbang.

Demikian untuk mewujudkan tujuan nasional seperti yang tercantum dalam pembukaan dan batang tubuh UUD 1945, maka Tap MPR No. IV/MPR/1999 tentang Garis-Garis Besar Haluan Negara telah menetapkan tentang arah dan kebijaksanaan pemerintah dalam bidang pendidikan sebagai berikut : "Mengembangkan kualitas sumber daya manusia sedini mungkin secara terarah, terpadu dan menyeluruh melalui proaktif dan reaktif oleh seluruh komponen bangsa agar generasi muda dapat berkembang secara optimal disertai dengan hak dukungan dan lindungan sesuai dengan potensinya (1999:28).

Untuk merealisasikan bunyi pasal 31 ayat 2 UUD 1945 tentang adanya Undang-Undang yang mengatur system pengajaran, maka pemerintah telah membuat UU No. 20 Tahun 2003 tentang system pendidikan nasional dengan menggunakan strategi belajar ini diharapkan hasil belajar mata pelajaran Biologi/IPA pada siswa Kelas VIII-B Semester Ganjil Tahun pelajaran 2019/2020. di SMP Negeri 1 Sekaran, Kabupaten Lamongan mencapai suatu hasil yang optimal. Beberapa alasan peneliti mengembangkan teknik pembelajaran mata pelajaran Biologi/IPA disebabkan karena didalam kurikulum mata pelajaran Biologi/IPA dapat membantu siswa untuk: (1) menjalani kehidupan sehari-hari secara efektif, (2) memahami dunianya dan hal-hal yang mempengaruhinya., (3) memanfaatkan kesempatan untuk mengembangkan kemampuan bertikir kreatif, fleksibel, dan inovatif, (4) mengembangkan pengertian tentang konsep-konsep Biologi/IPA, (5) menilai dan menggunakan produk teknologi, (6) memahami bahwa karir dalam Biologi/IPA dan teknologi cocok bagi pria dan wanita, (7) membuat penilaian tentang isu-isu yang berkenaan dengan lingkungan alam dan buatan, (8) bertanggung jawab terhadap perbaikan kualitas lingkungan, (9) memberikan pemecahan pada dilema moral sehubungan dengan isu-isu Biologi/IPA dan teknologi, dan (10) menyiapkan diri untuk studi pada tingkatan yang lebih lanjut.

Tujuan penelitian tindakan kelas ini untuk meningkatkan prestasi belajar siswa pada mata pelajaran Biologi/IPA pada siswa Kelas VIII-B Semester Ganjil dengan menggunakan metode Diversity of Student Stategy Learning (Strategi Pembelajaran yang mempertimbangkan keragaman siswa) sebagai metode pembelajaran .

\section{METODE}

Desain penelitian yang dipilih dalam penelitian ini adalah penelitian tindakan kelas yang dirancang melalui siklus tindakan. Prosedur untuk setiap siklus adalah perencanaan, pelaksanaan tindakan, pengamatan, dan refleksi. Prosedur setiap tindakan kelas ditunjukkan pada gambar di bawah ini. 
KARANGAN: Jurnal Kependidikan, Pembelajaran, dan Pengembangan, Vol 02, No 01, Bln Feb, Tahun 2020, Hal 32 - 41

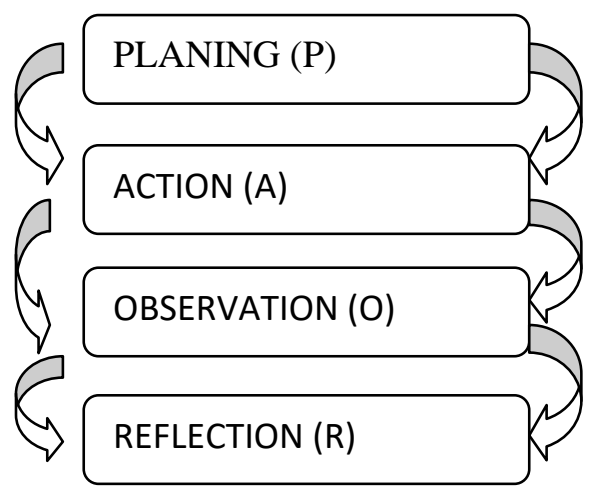

Penelitian tindakan kelas ini dilaksanakan di SMP Negeri 1 Sekaran tahun pelajaran 2019/2020. Penelitian ini dirancang dalam dua siklus, yaitu siklus pertama dan siklus kedua. Setiap siklus dilaksanakan selama dua jam pelajaran. Setiap siklus terdiri atas empat rencana tindakan, sebagai berikut:

\section{Penyusunan Rencana Tindakan}

Dalam penyusunan rencana tindakan ini guru mempersiapkan bahan untuk kegiatan kelas yang meliputi: menganalisis materi pembelajaran, menentukan materi pembelajaran, menelaah buku Biologi (IPA), menyusun perangkat pembelajaran (silabus, PSP, RP), dan penyusunan instrument penjaring data.

\section{Pelaksanaan Tindakan}

Pelaksanaan tindakan siklus I terdiri dari dua pertemuan. Pertemuan pertama (2 jam pelajaran) adalah untuk mencapai tujuan pembelajaran pada materi Biologi/IPA dengan metode Diversity of Student Stategy Learning (Strategi Pembelajaran yang mempertimbangkan keragaman siswa) di sekolah yang dilanjutkan di rumah.

Selanjutnya pertemuan kedua ( 2 jam pelajaran) dengan kegiatan membahas tugas pertemuan I dengan menggunakan metode Diversity of Student Stategy Learning (Strategi Pembelajaran yang mempertimbangkan keragaman siswa) yaitu dengan metode tanya jawab. Pada pertemuan kedua ini diakhiri dengan tes (evaluasi).

Siklus II dilaksanakan berdasarkan hasil refleksi siklus I. Jumlah pertemuan dan jam tatap muka disesuaikan berdasarkan temuan pada siklus I. Kolaborator yang dilibatkan dalam pelaksanaan tindakan ini adalah guru Biologi/IPA serta siswa tempat guru melaksanakan penelitian tindakan kelas ini. Guru sebagai kolaborator akan mengamati pelaksanaan KBM dengan menggunakan pedoman observasi yang telah disiapkan. Kolaborator dari siswa adalah respon dan jawaban siswa ketika KBM berlangsung.

\section{HASIL DAN PEMBAHASAN}

\section{Siklus I}

Adapun hasil observasi siklus I pada observasi pelaksanaan tindakan kelas ini diikuti oleh 25 siswa, seluruhnya Siswa Kelas VIII-B Semester Ganil di SMP Negeri 1 Sekaran, Kabupaten Lamongan pada Tahun Pelajaran 2019/2020. Hasil 
pengamatan terhadap metode pemberian tugas ini menekankan pada metode Tanya jawab dan tugas tertulis dengan alokasi waktu dua kali pertemuan, masing-masing pertemuan 2 x 40. Pertemuan I untuk menyelesaikan seluruh rincian kegiatan utama yaitu Tanya jawab dan tugas tertulis untuk pembahasan materi pelajaran Biologi/IPA dengan Materi Sistem gerak pada manusia .

Pada pertemuan I siswa belum dapat menyelesaikan tugasnya sehingga tugas tersebut dikerjakan di rumah. Hasil kegiatan belajar siswa pada pertemuan II adalah membahas tugas yang dikerjakan di rumah. Guru memeriksa tugas siswa dilanjutkan tany jawab yang berkisar pada tugas tersebut. Selanjutnya untuk mengukur keberhasilan siswa dalam penguasaan materi guru mengadakan post test.

Hasil pengamatan guru terhadap semua kerjaan pembelajaran Siswa Kelas VIII-B Semester Ganil di SMP Negeri 1 Sekaran, Kabupaten Lamongan pada Tahun Pelajaran 2019/2020 baik pertemuan I dan II menggunakan lembar observasi, yang meliputi: identifikasi perencanaan pembelajaran, pengamatan pelaksanaan pembelajaran, dan identifikasi pelaksanaan pembelajaran.

Hasil Pengamatan Siswa yang mengikuti Kegiatan Belajar Mengajar Pada siklus I

\begin{tabular}{|c|c|c|c|c|c|c|c|}
\hline \multirow{2}{*}{ No } & \multirow{2}{*}{ Nama Siswa } & \multicolumn{3}{|c|}{ Aktivitas } & \multicolumn{3}{|c|}{ Perhatian } \\
\hline & & $\mathrm{B}$ & $\mathrm{C}$ & $\mathrm{K}$ & B & $\mathrm{C}$ & K \\
\hline 1 & ALVIANSYAH BINTANG P. & V & & & V & & \\
\hline 2 & ARYA UYUT SAWEGAH & V & & & V & & \\
\hline 3 & ATTYA RAFFA DINA N. & $\mathrm{V}$ & & & & $\mathrm{V}$ & \\
\hline 4 & AURA KHUSAYNIYAHDEVI A.S. & & V & & & V & \\
\hline 5 & AYUNUR KUMALA SARI & V & & & & V & \\
\hline 6 & DELLA AGUSTINA & V & & & & & V \\
\hline 7 & DIEGO JULIOS OKTA R. & V & & & & & V \\
\hline 8 & EKYJUNNATA MARIAN & & V & & & & V \\
\hline 9 & M. AUONUTRIONO & & & V & & & V \\
\hline 10 & M. YAZID AL-BUSTHOMI & & & V & & & V \\
\hline 11 & MOCHAMMAD RISKY & V & & & V & & \\
\hline 12 & MUHAMMAD FHARIL RIZKY & V & & & V & & \\
\hline 13 & MUHAMMAD HASAN R.D. & V & & & V & & \\
\hline 14 & NABILLA NUR SYAIDAH & V & & & V & & \\
\hline 15 & RAHHUL PUTRA MAULANA & V & & & & V & \\
\hline 16 & RENO AZUKHRUF M. & & V & & & V & \\
\hline 17 & ROHMA SEPTIA WULANDARI & V & & & & V & \\
\hline 18 & ROIKHAN TRISAKTI & V & & & & & V \\
\hline 19 & SHARETA HAYATA V.C. & V & & & & & V \\
\hline 20 & TIGOR PERMANA & & V & & & & $\mathrm{V}$ \\
\hline 21 & AJIMUSTIKA CANDRA & & & V & & & V \\
\hline 22 & RAGIL FEBY SUSANTO & & & V & & & V \\
\hline 23 & ADITYA DWIFIRNANDA & V & & & V & & \\
\hline 24 & AHMAD KHOIRUN NAJWA & V & & & V & & \\
\hline 25 & AHMAD SIGIT PRAYOGO & V & & & V & & \\
\hline & & 17 & 4 & 4 & 9 & 6 & 10 \\
\hline & & $68 \%$ & $16 \%$ & $16 \%$ & $36 \%$ & $24 \%$ & $40 \%$ \\
\hline
\end{tabular}

Dari data di atas dapat kita lihat dari hasil aktifitas siswa yang memiliki aktifitas baik dalam kegiatan belajar sebanyak 17 (68\%) dan sedang sebanyak 4 
KARANGAN: Jurnal Kependidikan, Pembelajaran, dan Pengembangan, Vol 02, No 01, Bln Feb, Tahun 2020, Hal $32-41$

(16\%) serta sebanyak $4(16 \%)$ menunjukkan aktifitas kurang. Sedangkan hasil pengamatan dari sudut perhatian siswa dalam kegiatan belajar, siswa yang memiliki perhatian baik sebanyak $9(36 \%)$, yang memiliki perhatian sebanyak 6 (24\%) dan perhatian kurang 10 (40\%).

Dari data di atas dapat kita simpulkan bahwa dengan metode Diversity of Student Stategy Learning (Strategi Pembelajaran yang mempertimbangkan keragaman siswa) dapat meningkatkan aktifitas dan perhatian siswa pada pelajaran Biologi/IPA. Dengan menggunakan metode Diversity of Student Stategy Learning (Strategi Pembelajaran yang mempertimbangkan keragaman siswa) tersebut belum dinyatakan tuntas. Maka perlu diadakan kegiatan penelitian pada siklus yang ke 2

Hasil Prestasi Belajar Siswa pada Siklus I

\begin{tabular}{lll}
\hline No & Nama Siswa & Hasil Prestasi Belajar \\
\hline 1 & ALVIANSYAH BINTANG P. & 66 \\
\hline 2 & ARYA UYUT SAWEGAH & 67 \\
\hline 3 & ATIYA RAFFA DINA N. & 65 \\
\hline 4 & AURA KHUSAYNIYAH DEVI A.S. & 66 \\
\hline 5 & AYU NUR KUMALA SARI & 63 \\
\hline 6 & DELLA AGUSTINA & 70 \\
\hline 7 & DIEGO JULIOS OKTA R. & 71 \\
\hline 8 & EKY JUNNATA MARIAN & 65 \\
\hline 9 & M. AGUNG TRIONO & 70 \\
\hline 10 & M. YAZID AL-BUSTHOMI & 71 \\
\hline 11 & MOCHAMMAD RISKY & 68 \\
\hline 12 & MUHAMMAD FHARIL RIZKY & 73 \\
\hline 13 & MUHAMMAD HASAN R.D. & 74 \\
\hline 14 & NABILLA NUR SYAIDAH & 63 \\
\hline 15 & RAHHUL PUTRA MAULANA & 70 \\
\hline 16 & RENO AZUKHRUF M. & 71 \\
\hline 17 & ROHMA SEPTIA WULANDARI & 65 \\
\hline 18 & ROIKHAN TRI SAKTI & 70 \\
\hline 19 & SHARETA HAYATA V.C. & 71 \\
\hline 20 & TIGOR PERMANA & 68 \\
\hline 21 & AJI MUSTIKA CANDRA & 73 \\
\hline 22 & RAGIL FEBY SUSANTO & 66 \\
\hline 23 & ADITYA DWI FIRNANDA & 63 \\
\hline 24 & AHMAD KHOIRUN NAJWA & 70 \\
\hline 25 & AHMAD SIGIT PRAYOGO & 71 \\
\hline Jumlah & 1710 \\
\hline Rata rata & 68.40 \\
\hline & &
\end{tabular}

\section{Siklus II}

\section{Refleksi Siklus I}

Penggunaan metode Diversity of Student Stategy Learning (Strategi Pembelajaran yang mempertimbangkan keragaman siswa) dalam kegiatan pembelajaran ini telah berhasil pada siklus I. Berdasarkan refleksi pada siklus I, aktivitas belajar siswa cukup optimal. Siswa merasa mudah memahami materi pembelajarn, siswa sangat antusisas dan aktif mengikuti kegiatan belajar mengajar. 


\section{Pelaksanaan Tindakan Siklus II}

Tindakan pada siklus II tidak dilaksanakan karena siklus I sudah cukup berhasil. Hasil kegiatan pembelajaran yang tampak pada siklus I sudah menunjukkan ketuntasan belajar.

Hasil Pengamatan Siswa yang mengikuti Kegiatan Belajar Mengajar Pada siklus II.

\begin{tabular}{|c|c|c|c|c|c|c|c|}
\hline \multirow{2}{*}{$\begin{array}{l}\mathrm{N} \\
\mathrm{O}\end{array}$} & \multirow{2}{*}{ Nama Siswa } & \multicolumn{3}{|c|}{ Aktivitas } & \multicolumn{3}{|c|}{ Perhatian } \\
\hline & & $\mathrm{B}$ & $\mathrm{C}$ & $\mathrm{K}$ & $\mathrm{B}$ & $\mathrm{C}$ & $\mathrm{K}$ \\
\hline 1 & ALVIANSYAH BINTANG P. & $\mathrm{V}$ & & & $\mathrm{V}$ & & \\
\hline 2 & ARYA UYUT SAWEGAH & $\mathrm{V}$ & & & $\mathrm{V}$ & & \\
\hline 3 & ATIYA RAFFA DINA N. & $\mathrm{V}$ & & & $\mathrm{V}$ & & \\
\hline 4 & AURA KHUSAYNIYAH DEVI A.S. & $\mathrm{V}$ & & & & $\mathrm{V}$ & \\
\hline 5 & AYU NUR KUMALA SARI & & $\mathrm{V}$ & & & $\mathrm{V}$ & \\
\hline 6 & DELLA AGUSTINA & & & $\mathrm{V}$ & & & $\mathrm{V}$ \\
\hline 7 & DIEGO JULIOS OKTA R. & $\mathrm{V}$ & & & $\mathrm{V}$ & & \\
\hline 8 & EKY JUNNATA MARIAN & $\mathrm{V}$ & & & $\mathrm{V}$ & & \\
\hline 9 & $\overline{\mathrm{M} .}$ AGUNG TRIONO & $\mathrm{V}$ & & & $\mathrm{V}$ & & \\
\hline 10 & M. YAZID AL-BUSTHOMI & $\mathrm{V}$ & & & $\mathrm{V}$ & & \\
\hline 11 & MOCHAMMAD RISKY & $\mathrm{V}$ & & & $\mathrm{V}$ & & \\
\hline 12 & MUHAMMAD FHARIL RIZKY & $\mathrm{V}$ & & & $\mathrm{V}$ & & \\
\hline 13 & MUHAMMAD HASAN R.D. & $\mathrm{V}$ & & & $\mathrm{V}$ & & \\
\hline 14 & NABILLA NUR SYAIDAH & $\mathrm{V}$ & & & $\mathrm{V}$ & & \\
\hline 15 & RAHHUL PUTRA MAULANA & $\mathrm{V}$ & & & $\mathrm{V}$ & & \\
\hline 16 & RENO AZUKHRUF M. & $\mathrm{V}$ & & & & $\mathrm{V}$ & \\
\hline 17 & ROHMA SEPTIA WULANDARI & & $\mathrm{V}$ & & & $\mathrm{V}$ & \\
\hline 18 & ROIKHAN TRI SAKTI & & & $\mathrm{V}$ & & & $\mathrm{V}$ \\
\hline 19 & SHARETA HAYATA V.C. & $\mathrm{V}$ & & & $\mathrm{V}$ & & \\
\hline 20 & TIGOR PERMANA & $\mathrm{V}$ & & & $\mathrm{V}$ & & \\
\hline 21 & AJI MUSTIKA CANDRA & $\mathrm{V}$ & & & $\mathrm{V}$ & & \\
\hline 22 & RAGIL FEBY SUSANTO & $\mathrm{V}$ & & & $\mathrm{V}$ & & \\
\hline 23 & ADITYA DWI FIRNANDA & $\mathrm{V}$ & & & $\mathrm{V}$ & & \\
\hline 24 & AHMAD KHOIRUN NAJWA & $\mathrm{V}$ & & & $\mathrm{V}$ & & \\
\hline 25 & AHMAD SIGIT PRAYOGO & $\mathrm{V}$ & & & $\mathrm{V}$ & & \\
\hline \multicolumn{2}{|c|}{ Jumlah } & 21 & 2 & 2 & 19 & 4 & 2 \\
\hline \multirow{2}{*}{\multicolumn{2}{|c|}{ Prosentase }} & 84 & $8 \%$ & $8 \%$ & 76 & 16 & $8 \%$ \\
\hline & & $\%$ & & & $\%$ & $\%$ & \\
\hline
\end{tabular}

Dari data di atas dapat kita lihat dari hasil aktifitas siswa yang memiliki aktifitas baik dalam kegiatan belajar sebanyak $21(84 \%)$ dan sedang sebanyak 2 (8\%) serta sebanyak 2 (8\%) menunjukkan aktifitas kurang. Sedangkan hasil pengamatan dari sudut perhatian siswa dalam kegiatan belajar, siswa yang memiliki perhatian baik sebanyak 19 (76\%), perhatian orang tua sebanyak $4(16 \%)$ dan perhatian kurang 2 (8\%).

Dari data di atas dapat kita simpulkan bahwa dengan metode Diversity of Student Stategy Learning (Strategi Pembelajaran yang mempertimbangkan keragaman siswa) dapat meningkatkan aktifitas dan perhatian siswa pada pelajaran Biologi/IPA. Dengan menggunakan metode Diversity of Student Stategy Learning (Strategi Pembelajaran yang mempertimbangkan keragaman siswa) tersebut dinyatakan tuntas. Maka perlu diadakan kegiatan penelitian pada siklus berikutnya 
KARANGAN: Jurnal Kependidikan, Pembelajaran, dan Pengembangan, Vol 02, No 01, Bln Feb, Tahun 2020, Hal $32-41$

Hasil Prestasi Belajar Siswa pada Siklus II

\begin{tabular}{|c|c|c|}
\hline No & Nama Siswa & $\begin{array}{c}\text { Hasil Prestasi } \\
\text { Belajar }\end{array}$ \\
\hline 1 & ALVIANSYAH BINTANG P. & 85 \\
\hline 2 & ARYA UYUT SAWEGAH & 96 \\
\hline 3 & ATIYA RAFFA DINA N. & 100 \\
\hline 4 & AURA KHUSAYNIYAH DEVI A.S. & 88 \\
\hline 5 & AYU NUR KUMALA SARI & 75 \\
\hline 6 & DELLA AGUSTINA & 75 \\
\hline 7 & DIEGO JULIOS OKTA R. & 64 \\
\hline 8 & EKY JUNNATA MARIAN & 93 \\
\hline 9 & M. AGUNG TRIONO & 74 \\
\hline 10 & M. YAZID AL-BUSTHOMI & 81 \\
\hline 11 & MOCHAMMAD RISKY & 85 \\
\hline 12 & MUHAMMAD FHARIL RIZKY & 89 \\
\hline 13 & MUHAMMAD HASAN R.D. & 89 \\
\hline 14 & NABILLA NUR SYAIDAH & 78 \\
\hline 15 & RAHHUL PUTRA MAULANA & 70 \\
\hline 16 & RENO AZUKHRUF M. & 93 \\
\hline 17 & ROHMA SEPTIA WULANDARI & 85 \\
\hline 18 & ROIKHAN TRI SAKTI & 93 \\
\hline 19 & SHARETA HAYATA V.C. & 85 \\
\hline 20 & TIGOR PERMANA & 93 \\
\hline 21 & AJI MUSTIKA CANDRA & 52 \\
\hline 22 & RAGIL FEBY SUSANTO & 74 \\
\hline 23 & ADITYA DWI FIRNANDA & 81 \\
\hline 24 & AHMAD KHOIRUN NAJWA & 89 \\
\hline 25 & AHMAD SIGIT PRAYOGO & 70 \\
\hline \multicolumn{2}{|c|}{ Jumlah } & 2057 \\
\hline \multicolumn{2}{|c|}{ Rata rata } & 82.28 \\
\hline
\end{tabular}

Kegiatan belajar mengajar dengan menggunakan metode Diversity of Student Stategy Learning (Strategi Pembelajaran yang mempertimbangkan keragaman siswa) dapat berjalan dengan optimal. Kemampuan dasar pada materi pembelajaran hubungan pemerintahan pusat dan daerah dapat tercapai dengan baik. Hal ini dapat terlihat pada hasil evaluasi siswa yang mencapai ketuntasan 78,25\%.

Pada Siklus I data di atas dapat kita lihat dari hasil aktifitas siswa yang memiliki aktifitas baik dalam kegiatan belajar sebanyak $17(68 \%)$ dan sedang sebanyak $4(16 \%)$ serta sebanyak $4(16 \%)$ menunjukkan aktifitas kurang. Sedangkan hasil pengamatan dari sudut perhatian siswa dalam kegiatan belajar, siswa yang memiliki perhatian baik sebanyak 9 (36\%), yang memiliki perhatian sebanyak 6 (24\%) dan perhatian kurang 10 (40\%).

Dari data di atas dapat kita simpulkan bahwa dengan metode Diversity of Student Stategy Learning (Strategi Pembelajaran yang mempertimbangkan keragaman siswa) dapat meningkatkan aktifitas dan perhatian siswa pada pelajaran Biologi/IPA. Dengan menggunakan metode Diversity of Student Stategy Learning (Strategi Pembelajaran yang mempertimbangkan keragaman siswa) tersebut Belum dinyatakan Tuntas. Maka perlu diadakan kegiatan penelitian pada siklus yang ke 2

Pada Siklus II yang memiliki hasil data di atas dapat kita lihat dari hasil aktifitas siswa yang memiliki aktifitas baik dalam kegiatan belajar sebanyak 21 (84\%) dan sedang sebanyak $2(8 \%)$ serta sebanyak $2(8 \%)$ menunjukkan aktifitas kurang. Sedangkan hasil pengamatan dari sudut perhatian siswa dalam kegiatan belajar, siswa yang memiliki perhatian baik sebanyak 19 (76\%), perhatian orang tua sebanyak $4(16 \%)$ dan perhatian kurang $2(8 \%)$. 
Dari data di atas dapat kita simpulkan bahwa dengan metode Diversity of Student Stategy Learning (Strategi Pembelajaran yang mempertimbangkan keragaman siswa) dapat meningkatkan aktifitas dan perhatian siswa pada pelajaran Biologi/IPA. Dengan menggunakan metode Diversity of Student Stategy Learning (Strategi Pembelajaran yang mempertimbangkan keragaman siswa) tersebut dinyatakan Tuntas. Maka tidak perlu diadakan kegiatan penelitian pada siklus berikutnya

\section{SIMPULAN}

Untuk mencapai keberhasilan dalam kegiatan belajar mengajar di perlukan suatu metode sesuai dengan judul penelitian tindakan kelas ini maka metode yang dipergunakan adalah metode Diversity of Student Stategy Learning (Strategi Pembelajaran yang mempertimbangkan keragaman siswa). Metode ini dipergunakan pada saat proses belajar mengajar pada bidang studi Biologi/IPA. Maka dengan dipergunakan metode tersebut akan senantiasa anak aktif dalam belajar. Dengan demikian semakin banyak diberikan tugas-tugas kepadanya maka anak akan mudah memahami materi pembelajaran Biologi/IPA, maka akan mengakibatkan prestasi belajar semakin meningkat. Pada Siklus I data di atas dapat kita lihat dari hasil aktifitas siswa yang memiliki aktifitas baik dalam kegiatan belajar sebanyak 17 (68\%) dan sedang sebanyak 4 (16\%) serta sebanyak 4 (16\%) menunjukkan aktifitas kurang. Sedangkan hasil pengamatan dari sudut perhatian siswa dalam kegiatan belajar, siswa yang memiliki perhatian baik sebanyak $9(36 \%)$, yang memiliki perhatian sebanyak $6(24 \%)$ dan perhatian kurang 10 (40\%).

Dari data di atas dapat kita simpulkan bahwa dengan metode Diversity of Student Stategy Learning (Strategi Pembelajaran yang mempertimbangkan keragaman siswa) dapat meningkatkan aktifitas dan perhatian siswa pada pelajaran Biologi/IPA. Dengan menggunakan metode Diversity of Student Stategy Learning (Strategi Pembelajaran yang mempertimbangkan keragaman siswa) tersebut Belum dinyatakan Tuntas. Maka perlu diadakan kegiatan penelitian pada siklus yang ke 2

Pada Siklus II yang memiliki hasil data di atas dapat kita lihat dari hasil aktifitas siswa yang memiliki aktifitas baik dalam kegiatan belajar sebanyak 21 (84\%) dan sedang sebanyak $2(8 \%)$ serta sebanyak $2(8 \%)$ menunjukkan aktifitas kurang. Sedangkan hasil pengamatan dari sudut perhatian siswa dalam kegiatan belajar, siswa yang memiliki perhatian baik sebanyak 19 (76\%), perhatian orang tua sebanyak $4(16 \%)$ dan perhatian kurang $2(8 \%)$.

Dari data di atas dapat kita simpulkan bahwa dengan metode Diversity of Student Stategy Learning (Strategi Pembelajaran yang mempertimbangkan keragaman siswa) dapat meningkatkan aktifitas dan perhatian siswa pada pelajaran Biologi/IPA. Dengan menggunakan metode Diversity of Student Stategy Learning (Strategi Pembelajaran yang mempertimbangkan keragaman siswa) tersebut dinyatakan Tuntas.

\section{DAFTAR RUJUKAN}

Bimo Walgito, 1980. Psychology Sosial. Yogyakarta: Yayasan Penerbit Umum. Drs. Dariyanto, 1983. Tujuan, Metode dan Satuan Pelajaran dan Proses Belajar Mengajar. Yogyakarta: Andi Offset.

Departemen Pendidikan dan Kebudayaan, 1992. Himpunan Perundang-Undangan RI bidang Pendidikan dan Kebudayaan. Jakarta

Mokhamad Ismail,2009. Biologi SMP. Yokyakarta: Pustaka Widyatama 
KARANGAN: Jurnal Kependidikan, Pembelajaran, dan Pengembangan, Vol 02, No 01, Bln Feb, Tahun 2020, Hal $32-41$

Purwodarminto, 1984. Kamus Umum Pembelajaran Biologi/IPA, Jakarta: Balai Pustaka.

Siti Zubaidah dkk, 2017. Ilmu Pengetahuan Alam.Jakarta:Pusat Kurikulum dan Perbukuan Kemendikbud.

Winarno Surachmad, 1984. Pengantar Interelasi Belajar Mengajar, Bandung: Tarsito. 